\title{
Consent to autopsy for neonates
}

\author{
H E McHaffie, P W Fowlie, R Hume, I A Laing, D J Lloyd, A J Lyon
}

\begin{abstract}
Objectives-To determine parents' views on autopsy after treatment withdrawal. Design-Face to face interviews with 59 sets of bereaved parents (108 individual parents) for whose 62 babies there had been discussion of treatment withdrawal. Results-All except one couple were asked for permission for postmortem examination; $38 \%$ refused. The main reasons for declining were concerns about disfigurement, a wish to have the child left in peace, and $a$ feeling that an autopsy was unnecessary because the parents had no unanswered questions. The diagnosis, the age of the child, and the approach of the consultant appeared to influence consent rates. Of those who agreed to autopsies, $92 \%$ were given the results by the neonatologist concerned. Whether or not they had agreed to the procedure, at 13 months no parent expressed regrets about their decision.
\end{abstract}

Conclusions-Autopsy rates in the East of Scotland stand at $62 \%$. Parents' perceptions are an important element in consent to postmortem examination.

(Arch Dis Child Fetal Neonatal Ed 2001;85:F4-F7)

Keywords: autopsy; withdrawal of treatment; consent

University of

Edinburgh,

Edinburgh, Scotland

$\mathrm{H}$ E McHaffie

Ninewells Hospital and Medical School,

Dundee, Scotland, UK

P W Fowlie

Department of

Developmental

Medicine, University

of Dundee

R Hume

Simpson Memorial Maternity Pavilion, Edinburgh

I A Laing

A J Lyon

Aberdeen Maternity Hospital, Aberdeen, Scotland, UK

D J Lloyd

Correspondence to: Dr McHaffie, 12 Mayburn Terrace, Loanhead, Midlothian EH20 9EJ, Scotland, UK

hazel@mchaffie.f9.co.uk

Accepted 13 December 2000 babies vary from $48 \%$ to $79 \% .^{7-13}$ There is documented evidence, however, that rates are falling world wide, ${ }^{61415}$ and, in one centre, for neonatal deaths, the decline over 10 years was from $71 \%$ to $48 \%{ }^{7}$ Public anxiety about organ removal seems likely to reduce these figures further.

Correlation with a range of factors such as maternal age, race, marital status, employment, socioeconomic influences, parity, gestation, birth weight, age of the baby, length of stay in a neonatal intensive care unit, and status of the requester has been examined, ${ }^{811} 1316$ but few associations found. However, it has been suggested that parents may be less likely to agree if the baby is extremely preterm, ${ }^{8}$ although there is no evidence that postmortem examination gives less new information in this group of infants.

For the parents themselves, the autopsy would appear to have special significance ${ }^{17}$ It provides information about what actually happened in their case. Even when a clear diagnosis has been established, totally new or important information is found in a significant number of autopsies. ${ }^{101518}$ It gives confirmation or otherwise of the accuracy of the diagnosis and the appropriateness of treatment given. Importantly it may also provide information about genetic or obstetric risk. Aside from these personal benefits, parents may gain comfort from knowing that knowledge gained may be used to help others, bringing good out of their tragedy. When children die after treatment withdrawal, there is an added dimension: the autopsy may confirm the wisdom of the decision to stop.

Knowing the statistics for consent and the demographic associations, however, provides only a partial picture. An important element may be parental perception. In this paper, we report results relating to parents' own ideas about autopsy, which formed part of a much larger study of their total experience of treatment withdrawal. The babies in the study died during the period September 1996 to August 1998, predating the public exposure of postmortem experiences of families in Bristol and Liverpool. Findings therefore relate to the experience of parents when there has been no effect from public alarm.

\section{Method}

SETTING

Three regional neonatal referral centres in the East of Scotland were selected, which provided a representative range of families.

Parents were eligible for inclusion if there had been any discussion about treatment limitation. The babies were those for whom there was a medical prognosis of either early death or severe impairment associated with a very poor quality of life. All three main categories of imperilled babies were represented: preterm delivery, congenital anomalies, asphyxia. Fifty nine of the 81 eligible families $(73 \%)$ participated. 
PROCEDURE

With ethics committee approval, parents were recruited at the time of first follow up clinic appointments with the neonatologist. Semistructured interviews were scheduled to take place three and 13 months after the death of the baby and to cover their whole experience of this pregnancy, birth, death, and bereavement. Tape recorded interviews lasted 1-5.25 hours. Three quarters of the parents were interviewed as a couple at the first point of enquiry and $80 \%$ at the second.

Data were entered on to a computer under predetermined variable names, and SPSS for the Apple Mac was used to analyse the resulting large volume of data. Twelve percent of the interviews were independently checked for accuracy of coding and interpretation by a practising paediatrician (PWF), and a further $10 \%$ by a student in medical ethics ( $R$ Bercovitch).

\section{RESPONDENTS}

A total of 59 families (108 parents) participated at three months, and $85 \%$ of them (50 families, 90 parents) again at 13 months. Most of the parents were in their thirties or older (60\% mothers, $67 \%$ fathers), with only $8 \%$ of the mothers and no fathers in their teens. Thirty one percent of the mothers were primigravidae.

Eight of the pregnancies resulted in multiple births. Sixteen of these babies were born alive and, of these, 11 were eligible for inclusion in the study, giving a total of 62 babies about whom there had been discussion concerning treatment limitation. Gestations ranged from 22 to 41 weeks (median 28 weeks), with nine babies born at less than 24 weeks. Most (38, $61 \%$ ) died within the first week of life, 23 living less than two days. However, six $(10 \%)$ lived for more than three months, one surviving almost nine months.

We report the parents' perceptions; no attempt was made to corroborate their information.

\section{Results}

All except one couple were asked for permission for autopsy. Broaching the subject was clearly a very delicate matter which parents reported finding "shocking" or upsetting.

Of the 58 families asked, 22 (38\%) refused permission for an autopsy. One or both parents in a further $11(19 \%)$ families were initially reluctant but were persuaded that it was the right thing to do. For three of these, it was reassurance that the procedure would be carried out with care and dignity that persuaded them to agree. Thus $36(62 \%)$ consented to autopsy. In three families, the parents themselves differed in their response to the request, and in only one of these was the procedure carried out.

REASONS FOR CONSENTING OR DECLINING The main reasons cited by the 36 sets of parents who consented were as follows.

- To obtain answers to their questions (23). Three specifically wanted confirmation of the diagnosis (one), and the rightness of
Table 1 Comparison of babies having autopsy or not by diagnosis

\begin{tabular}{lll}
\hline & Autopsy & No autopsy \\
\hline Asphyxia or brain damage & 9 & 2 \\
$\begin{array}{l}\text { Congenital anomalies excluding } \\
\quad \text { cardiac }\end{array}$ & 7 & 2 \\
$\begin{array}{l}\text { Cardiac anomalies } \\
\text { Preterm }\end{array}$ & 2 & 4 \\
\hline
\end{tabular}

their decision (two), although they showed that they were aware of the possibility that the autopsy might not offer them this reassurance.

- To help others (13). As one couple said: "Our heartbreak could be somebody else's gain."

- To obtain information that may influence future pregnancies (13).

One mother wanted the findings to use as evidence of negligence.

Twenty two $(38 \%)$ declined the procedure; for them it was undesirable or unnecessary. Their main stated reasons were as follows.

- Dread of the child being mutilated or subjected to further invasion (14). It is noteworthy that only one set of parents mentioned the issue of organ removal; they could not come to terms with the idea of the brain being removed.

- They had no further questions that they needed to be answered (9).

One parent did not want their child "to be a guinea pig", and one other believed the doctors only wanted an autopsy to find out if they had been right in their diagnosis. Two couples considered that the doctors should have had answers before withdrawing treatment and not after death.

COMPARISON OF FAMILIES WHO AGREED TO AUTOPSY WITH THOSE WHO DID NOT

These data from so few families are not robust enough to permit calculations of statistical significance, but some interesting comparisons between the two groups emerged. Notable differences related to diagnosis, the consultant concerned, and the age of the child.

As table 1 shows, most babies with a diagnosis of asphyxia, brain damage, or congenital anomalies (other than cardiac defects) did have autopsies. However, twice as many babies with cardiac anomalies did not. Of the 33 families with preterm infants, 18 consented to autopsy (gestation 22-31 weeks, age range $<1$ hour to 8 months) whereas 15 did not (gestation 23-28 weeks, age range $<1$ day to 6 months).

The second difference related to the approach of the doctor concerned. In all three units, it was stated policy for the consultant in charge of the baby to seek consent for this procedure. One couple reported being additionally visited by a pathologist who tried repeatedly to encourage them to consent. The number of referrals to the study by different consultants varied, and the different circumstances of each case may well have influenced the level of persuasion used. It is not possible to compare individual practices in any meaningful way, but the data suggest that consultants' rates of obtaining consent vary. In one unit where 
no-one other than the neonatologist ever seeks consent, and taking comparable numbers of referrals to the study and the same spread of diagnoses, one consultant obtained permission in $89 \%$ of his referrals, whereas a colleague had $80 \%$ declining autopsy.

The length of time babies live appeared to be a relevant factor. As many as $82 \%(9 / 11)$ of the babies who lived for a day or less had autopsies, and $75 \%(3 / 4)$ who lived for more than three months did so. In contrast, only $52 \%$ of the 44 babies who lived for 2-92 days had autopsies. An American study also found that rates of consent rose with increased postnatal age and increased length of stay in the neonatal intensive care unit. ${ }^{8}$

AUTOPSY FINDINGS

In our study, 34 of the 36 families (92\%) who had consented to autopsy reported having had discussion of the results at their follow up paediatric bereavement visit. Information from one family was missing. In the other case, the results had not been conveyed during the first visit but the parents expected a further appointment; they were unavailable for a second interview, however, so it is not known whether or not they did receive this information.

Reassurance that everything possible and appropriate had been done was identified by the parents as an important element in follow up care, and in many cases such reassurance could only come when the autopsy findings were available. In one case, it was only postmortem examination that could and did confirm a tentative diagnosis of an extremely rare condition, increasing the couple's respect for the neonatologist's skill and satisfaction with their care. However, in another case, reassurance could not be given. Even though this mother had legal assurance that she had a case against the hospital for negligence in labour, she felt no need to pursue it through the courts. She now had the facts and could "start to grieve."

SUBSEQUENT REGRETS

Thirteen months after the death of the infants, when asked if they had any regrets about the overall management of their case, no parent in our study mentioned their decision either to have or to decline autopsy for their children.

\section{Discussion}

The literature suggests that the single most common cause for not obtaining a postmortem examination is failure to ask for one. ${ }^{17}$ Our study shows that this is not the case in the neonatal units in the East of Scotland, where all except one of the families we studied were asked. We have no objective information about how hard consultants pressed for consent, but the data suggest that, in line with clinical expectation, more parents agreed to autopsy when the deaths were unexpected, unexplained, or may have carried a significant genetic component. It may be thought that when a "diagnostic 'gold standard' is available during life", 9 autopsies will add little information. When the causes appear obvious - for example, physiological immaturity - there may seem less need to carry out postmortem examination. However, it must be remembered that, when postmortem findings have been compared with antemortem diagnoses for the total perinatal population, errors of up to $45 \%$ of cases have been reported, ${ }^{18}$ and there is no evidence that autopsies performed on preterm infants are less likely to yield new information. ${ }^{8}$

Evidence appears inconclusive as to whether or not the identity of the person seeking consent matters. ${ }^{81416}$ In the study units, the practice is for the consultant to ask this question. Furthermore, in almost all cases, it is the same consultant who sees the parents at the follow up meeting when the postmortem findings are given: this was so for all except one couple in our study. Disturbing results have emerged from previous surveys in which relatives never received autopsy findings, were given them over the phone, or had no opportunity to discuss them with a doctor. ${ }^{17} 19$ The parents we interviewed not only identified a need to have face to face discussion and interpretation of the meaning of the findings with someone knowledgeable, but more than that, they wished for the person undertaking this task to be someone known and trusted, continuity being an important adjunct to trust. These are often hard messages to receive, and the support of those who shared the life and death of the baby is crucial at this time.

Although there is little to suggest that either epidemiological or demographic factors influence consent to autopsy, our study suggests that parental attitudes and beliefs do. Intuitively, it may be thought that parents may be more eager to have autopsy confirmation of a poor prognosis in cases where treatment was withdrawn. In reality, we found that only two parents cited this as an overt reason for consenting to a postmortem examination. Rather, when they themselves still have unanswered questions, they need facts that can be obtained after death to help to complete the picture of what went wrong. Conversely, however, when they are satisfied with current knowledge of the circumstances but the medical team still has unanswered questions, there may be resistance to anything else being done to a child who has already endured so much. Concerns about disfigurement are known to loom large in the minds of relatives contemplating autopsy, especially when children are concerned, ${ }^{17}{ }^{19}$ and our results confirm this as a major preoccupation with parents.

A recent survey of parental experience after loss of a pregnancy or baby found that one in 18 women who consented to autopsy subsequently regretted doing so, and three in ten women who had declined regretted their decision. ${ }^{20}$ Our numbers are too small for confident assertions, but no parent who either did or did not give permission for autopsy expressed subsequent regrets. A more structured and focused study is required to ascertain the longer 
term sequelae because clinical experience indicates that regrets may surface as long as a generation later.

\section{CONCLUSION}

Our findings suggest that parents' perceptions play a significant part in consent rates. From a medical point of view, convincing evidence exists of the vital role that autopsies play in accurate diagnosis and auditing patient care. ${ }^{15}$ Objectively, it can be argued that perinatal autopsies carry special benefits for parents in that alongside reassurance about the past, they may identify risks for the future. Valuable information that could influence future choices may be lost if permission is not given. But reasoned arguments carry only so much persuasive power; parents show that they may listen to advice but decide against autopsy for cultural, personal, or instinctive reasons.

Recent adverse attention to the subject by the media could conceivably undermine public confidence and further reduce rates of consent for full autopsy. A larger and more focused study is needed to determine whether or not recent revelations about the use of tissue or organs has had a damaging effect on parental trust, but it seems possible that a significant number of families will refuse permission. Some of them may well later regret that decision. The medical profession must respond swiftly. The Royal College of Pathologists has responded by drafting guidelines on the retention of tissues at postmortem examination. ${ }^{21}$ Those who work closely with these families must respond by listening carefully to the parents.

We are grateful to many colleagues for their contribution to this project but particularly members of the research team (Mr R Bercovitch, Dr K M Boyd, Professor A G M Campbell, Dr C H $M$ Walker), colleagues in the study units and in the Institute of Medical Ethics. The study was funded by The Scottish Executive. Our greatest debt is to the bereaved parents who so courageously shared their experiences and insights.
1 Dobson R. Bristol parents protest over removal of hearts. BMF 1999;318:486.

2 Dyer C. Government orders inquiry into removal of children's organs. BMf 1999;319:1518.

3 Dyer C. Bristol inquiry into baby deaths to move into new phase. BMF 2000;320:9.

4 Rushton DI. West Midlands perinatal mortality survey, 1987. An audit of 300 perinatal autopsies. Br f Obstet Gynaecol 1991;98:624-7.

5 Rushton DI. Prognostic role of the perinatal postmortem. Br F Hosp Med 1994;52:450-4.

6 Sirkia K, Saarinen-Pihkala UM, Hovi L, et al. Autopsy in children with cancer who die while in terminal care. Med Pediatr Oncol 1998;30:284-9.

7 Kumar P, Angst DB, Taxy J, et al. Neonatal autopsies: a 10-year experience. Arch Pediatr Adolesc Med 2000;154:38-42.

8 VanMarter LJ, Taylor F, Epstein MF. Parental and physician-related determinants of consent for neonatal autopsy. American fournal of Diseases in Children 1987;141:149-53.

9 Dhar V, Perlman M, Vilela MI, et al. Autopsy in a Neonatal Intensive Care Unit: utilization patterns and associations of clinicopathologic discordances. F Pediatr 1998;132:75-

10 Saller DN, Lesser KB, Harrel U, et al. The clinical utility of the perinatal autopsy. $\mathcal{F} A M A$ 1995;273:663-5.

11 Khong TY, Mansor FAW, Staples AJ. Are perinatal autopsy rates satisfactory? Med $\mathcal{F}$ Aust 1995;162:469-70.

12 Craft H, Brazy JE. Autopsy: high yield in neonatal population. American fournal of Diseases in Children 1986;140:1260-2

13 Maniscalco WM, Clarke TA. Factors influencing neonatal autopsy rate. American fournal of Diseases in Children 1982;136:781-4.

14 Khong TY. Improving perinatal autopsy rates: who is counselling bereaved parents for autopsy consent? Birth 1997;24:55-7.

15 Joint Working Party of the Royal College of Pathologists, the Royal College of Physicians of London and the Royal College of Surgeons of England. The Autopsy and audit. Lonlone of Surgeons

16 Landers S, Kurby R, Harvey B, et al. Characteristics of infants who undergo neonatal autopsy. $f$ Perinat 1994;14:204-7.

17 Riggs D, Weibley RE. Autopsies and the Pediatric Intensive Care Unit. Pediatr Crit Care 1994;41:1383-93.

18 Khong TY. The contribution of the pathologist after a perinatal loss: what should we be telling parents. Aust $N Z \mathcal{F}$ Obstet Gynaecol 1996;36:15-17.

19 McPhee SJ, Bottles K, Lo B, et al. To redeem them from death. Reactions of family members to autopsy. Am $\mathcal{F} M e d$ 1986;80:665-71.

20 Abdul RH, Khong TY. Perinatal infant postmortem examination. Survey of women's reactions to perinatal examination. Survey of women's
necropsy. BMF 1995;310:870-1.

21 Royal College of Pathologists. Consultation paper: guidelines for the retention of tissues at post-mortem examination. London: RCP, 2000. 